\title{
Development of a high-precision bladder hyperthermic intracavitary chemotherapy device for bladder cancer and pharmacokinetic study
}

Mingchen Ba ${ }^{1 *}$, Shuzhong Cui ${ }^{1 *}$, Hui Long ${ }^{2}$, Yuanfeng Gong ${ }^{1}$, Yinbing $\mathrm{Wu}^{1}$, Kunpeng Lin ${ }^{1}$, Yinuo Tu${ }^{1}$, Bahuo Zhang ${ }^{1}$ and Wanbo Wu ${ }^{1}$

\begin{abstract}
Background: Bladder hyperthermic intracavitary chemotherapy (HIVEC) has good effectiveness for bladder cancer, but conventional HIVEC systems lack precision and convenient application. To test the safety of a new HIVEC device (BR-TRG-II-type) in pigs and to perform a preliminary clinical trial in patients with bladder cancer.

Methods: This device was tested on six pigs to optimize the temperature and time parameters. Then, 165 patients (HIVEC after transurethral resection (TUR), $n=128$; or HIVEC, $n=37$ ) treated between December 2006 and December 2016 were recruited. Mitomycin C (MMC) was the chemotherapeutic agent. A serum pharmacokinetic study was performed. The primary endpoints were tumor recurrence, disease-free survival (DFS), and cumulative incidence rate (CIR) during follow-up. The adverse effects were graded.

Results: The animal experiment showed that $45^{\circ} \mathrm{C}$ for $1 \mathrm{~h}$ was optimal. HIVEC was successful, with the infusion tube temperature stably controlled at about $45^{\circ} \mathrm{C}$, and outlet tube temperature of about $43^{\circ} \mathrm{C}$ in all patients, for three sessions. Serum MMC levels gradually increased during HIVEC and decreased thereafter. The mean DFS was $39 \pm 3.21$ months (ranging from 8 to 78 months), and the DFS rate was $89.1 \%$ during follow-up. No adverse events occurred.
\end{abstract}

Conclusion: The use of the BR-TRG-II-type HIVEC device is feasible for the treatment of bladder cancer. Future clinical trials in patients with different stages of bladder cancer will further confirm the clinical usefulness of this device.

Trial registration: chictr.org.cn: ChiCTR1900022099 (registered on Mar. 252,019). Retrospectively registered.

Keywords: Hyperthermic intracavitary chemotherapy, Bladder cancer, Survival, Animal model

\section{Background}

Bladder cancer ranks among the top five malignant tumors worldwide, with over 70,000 new patients diagnosed with bladder cancer each year in the United States [1]. The standard procedure for bladder cancer removal is still transurethral resection (TUR) or surgical resection [2], but recurrence is always a major concern. As

\footnotetext{
* Correspondence: bamingchen@126.com; cuishuzhong@126.com ${ }^{1}$ Intracelom Hyperthermic Perfusion Therapy Center, Cancer Hospital of Guangzhou Medical University, No. 78 Hengzhigang Road, Guangzhou, Guangdong 510095, People's Republic of China

Full list of author information is available at the end of the article
}

much as $80 \%$ of patients with bladder cancer confined to bladder epithelium will experience disease recurrence, and up to $45 \%$ of patients with invasion of lamina propria and $10 \%$ with carcinoma in situ will experience disease progression without treatment [3]. Intravesical Bacillus Calmette-Guerin (BCG) is recommended as adjuvant therapy [4], but recurrence and progression occurs in a substantial proportion of patients [5]. Mitomycin C (MMC) is also recommended as adjuvant treatment, but its efficacy is limited [6-9]. TUR or surgical resection alone cannot be performed microscopically, and systemic chemotherapy has only limited efficacy

(C) The Author(s). 2019 Open Access This article is distributed under the terms of the Creative Commons Attribution 4.0 International License (http://creativecommons.org/licenses/by/4.0/), which permits unrestricted use, distribution, and 
against bladder cancer $[3,10]$. Therefore, preventing recurrence of bladder cancer after TUR and preventing progression in patients unsuitable for TUR or surgical resection remain major problems in oncology $[11,12]$.

Bladder hyperthermic intracavitary chemotherapy (HIVEC) combines the advantages of local hyperthermia with intracavitary chemotherapy, which have a synergistic or at least additive effect in preventing bladder cancer recurrence post TUR or surgical resection [13-16]. However, available systems have issues in the precision of temperature control to the target site $[6-9,11-14,16-19]$, limiting their efficacy and safety $[3,10,13-18]$.

The BR-TRG-I-type hyperthermic intraperitoneal perfusion chemotherapy (HIPEC) device is a recent HIPEC device now approved by the Chinese Food \& Drug Agency (license number 2009-3260924) and covered by two Chinese patents (ZL2006200613779 and ZL2006200613764). The BR-TRG-Itype HIPEC device has been shown to be safe and effective for the treatment of malignant ascites and peritoneal cancer [20]. The BR-TRG-I-type HIPEC device has been tested for hyperthermic intraperitoneal perfusion chemotherapy [21], but it is not suitable for bladder cancer. On the basis of the BR-TRG-I-type HIPEC device, we developed the BR-TRGII-type HIVEC device, which has been shown to be safe and efficient in preventing the recurrence of non-muscle invasive bladder cancer (NMIBC) after TUR and prolonging diseasefree survival (DFS) [12]. This device allows for a precise temperature $\left( \pm 0.2{ }^{\circ} \mathrm{C}\right)$ and flow $( \pm 5 \%)$ control [20]. Therefore, the aim of the present exploratory study was to test the safety of the device in pigs, and to perform a preliminary clinical trial in patients with bladder cancer treated.

\section{Methods}

\section{Animals}

Animal experiments with the BR-TRG-II-type HIVEC device were performed using six healthy female experimental pigs (Sus scrofa domesticus; $40-50 \mathrm{~kg}$, median $52.6 \mathrm{~kg}$; 4-6 months old, median 5 months) purchased from the Animal Experiments Center of Nanfang Medical University (Guangzhou, China). The experimental animals were sacrificed by intravenous air embolization after receiving general anesthesia with intravenous infusion of propofol (femoral vein, $3-8 \mathrm{ml} / \mathrm{h}$, adjusted according to the condition of the animals). This study was approved by the Ethics Committee of Animal Experiments of Guangzhou Medical University (No. GZMU ECAE 20060326), Guangzhou, China. All animals were handled humanely, and all means were taken to minimize suffering. All experiments were carried out according to the animal experiment principles from the US National Institutes of Health and according to the regulations from the Chinese government.

Under endotracheal anesthesia, 24 F 3-way Foley catheters were introduced into the bladder cavity, and $5 \mathrm{ml}$ of warm saline were injected to inflate the sac and fix the catheter in the bladder cavity. The BR-TRG-II-type HIVEC device (Fig. 1) was connected to the catheter and loaded with a solution of $60 \mathrm{mg}$ of MMC (Zhejiang Hisun pharmaceutical Limited by Share Ltd., Hangzhou, China) in $600 \mathrm{ml}$ of sterile saline. The perfusion rate of the MMC solution was set as $150-200 \mathrm{ml} / \mathrm{min}$. The experimental temperature and time (i.e., $44{ }^{\circ} \mathrm{C}, 46^{\circ} \mathrm{C}$, or $48^{\circ} \mathrm{C}$ for $60 \mathrm{~min}$ ) were set. The treatment temperature during HIVEC was measured by the device using temperature probes inserted in a blind pipe in an inflated water sac linked to an infusion tube near an infusion tube and in a blind pipe in an inflated water sac linked to an outlet tube near the 24 F 3-way Foley catheter (as shown in Fig. 2a b).

Based on the "resource equation" principle [22-24], on the results being observed, and on available resources, six pigs were randomized (random number table prepared by a third-party statistician) to the $44{ }^{\circ} \mathrm{C}, 46^{\circ} \mathrm{C}$, and $48^{\circ} \mathrm{C}$ groups ( 2 pigs/group). Before HIVEC, the perfusion liquid was adjusted to the proper temperature. Any temperature change was monitored closely by the temperature probes. HIVEC was performed once a week for 3 weeks. The Foley catheter was pulled out after every session. The bladder mucosa changes after HIVEC were assessed by cystoscopic observation under endotracheal anesthesia $[13,19]$. The observer was blind to grouping.

\section{Clinical trial}

Patients with bladder cancer were prospectively recruited from December 2006 to December 2016 at the Intracelom Hyperthermic Perfusion Therapy Center of the Cancer Hospital of Guangzhou Medical University. This study was retrospectively registered (chictr.org.cn: ChiCTR1900022099). The patients received TUR + HIVEC or HIVEC according to whether they were suitable or not for TUR [2]; there was no randomization for this part of the study, nor blinding. Bladder cancer was diagnosed and staged by cystoscopic observation, computerized tomography $(\mathrm{CT})$, and/or magnetic resonance imaging (MRI) examination.

The inclusion criteria were: 1) $\geq 18$ years of age; 2) diagnosis of bladder cancer by cystoscopic observation, CT, and/or MRI; 3) diagnosis confirmed by histopathological examination of a biopsy specimen; 4) no radiation therapy in the 4 weeks preceding enrollment; and 5) no chemotherapy in the 4 weeks preceding enrollment. The exclusion criteria were: 1) stage Ta bladder cancer; 2) known or possible bladder metastasis from other primary cancer; 3) known or possible bladder tumor expanding through the serosa, invading locally or metastasizing to other organs; 4) known or potential pregnancy; or 5) active inflammation or infection. Based on whether the patients were suitable for TUR or not, 


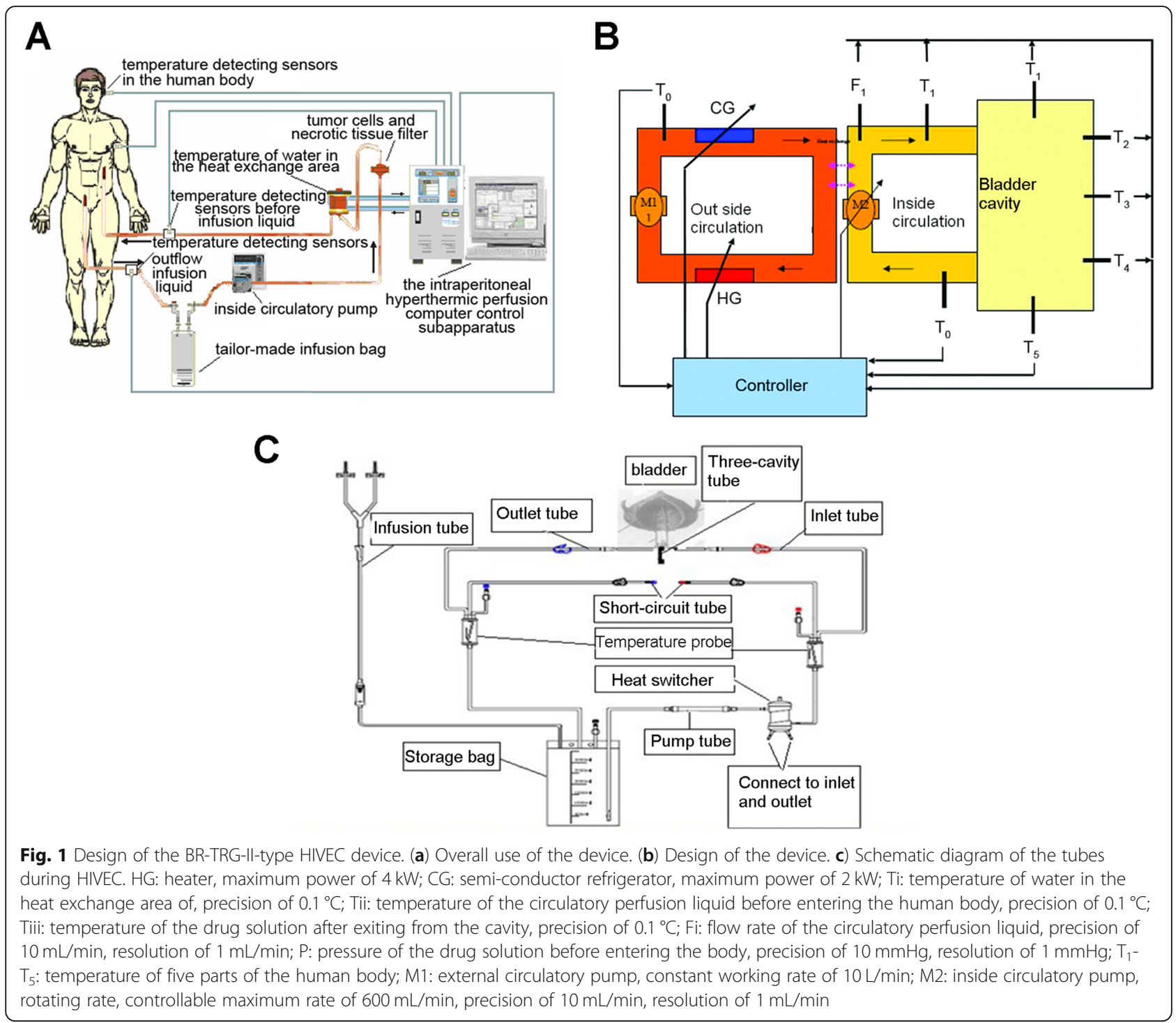

TUR + HIVEC or HIVEC was performed. TUR + HIVEC was performed for patients eligible for TUR but not for cystectomy and reconstruction because of comorbidities or incapacity to bear the surgical trauma. In patients unable to bear any surgery, HIVEC was performed.

All treatments were performed by our study team with clinical experience with TUR and HIVEC. This study was approved by the Medical Ethics Committee of the Cancer Hospital of Guangzhou Medical University (No. GZMU ECAE 20060326). Written informed consent was obtained from all patients. Some of the patients included in the present study were also included in a previous study by our group [12], but differences in the selection criteria resulted in different sample sizes and groups of patients between the two studies.

\section{Transurethral resection}

Cystoscopy was performed under epidural anesthesia. A 24Fr monopolar resectoscope system (Karl Storz, Tuttlingen,
Germany) was used for TUR. Under cystoscopy, the profile and margins of the tumor were first defined. Resection was then performed carefully to avoid perforation and wall distention. The emptied bladder was manually manipulated on the pubic symphysis in cases of poorly located tumors. Small and flat lesions were positioned between the resection loop and the end portion of the resectoscope sheath. Hemostasis was carefully performed after tumor removal $[13,19]$.

\section{HIVEC}

HIVEC was directly performed for patients unsuitable for TUR, or 0-1 days after TUR. To do so, 24 F 3-way Foley catheters were introduced into the bladder cavity for HIVEC, and $5 \mathrm{ml}$ of warm saline were injected to inflate the sac and fix the catheter in the bladder. The BR-TRGII type high-precision HIVEC device was connected to tubes (Guangzhou Bright Medical Technology Co., Ltd.). A bag containing $60 \mathrm{mg}$ of MMC in $500-700 \mathrm{ml}$ (average 


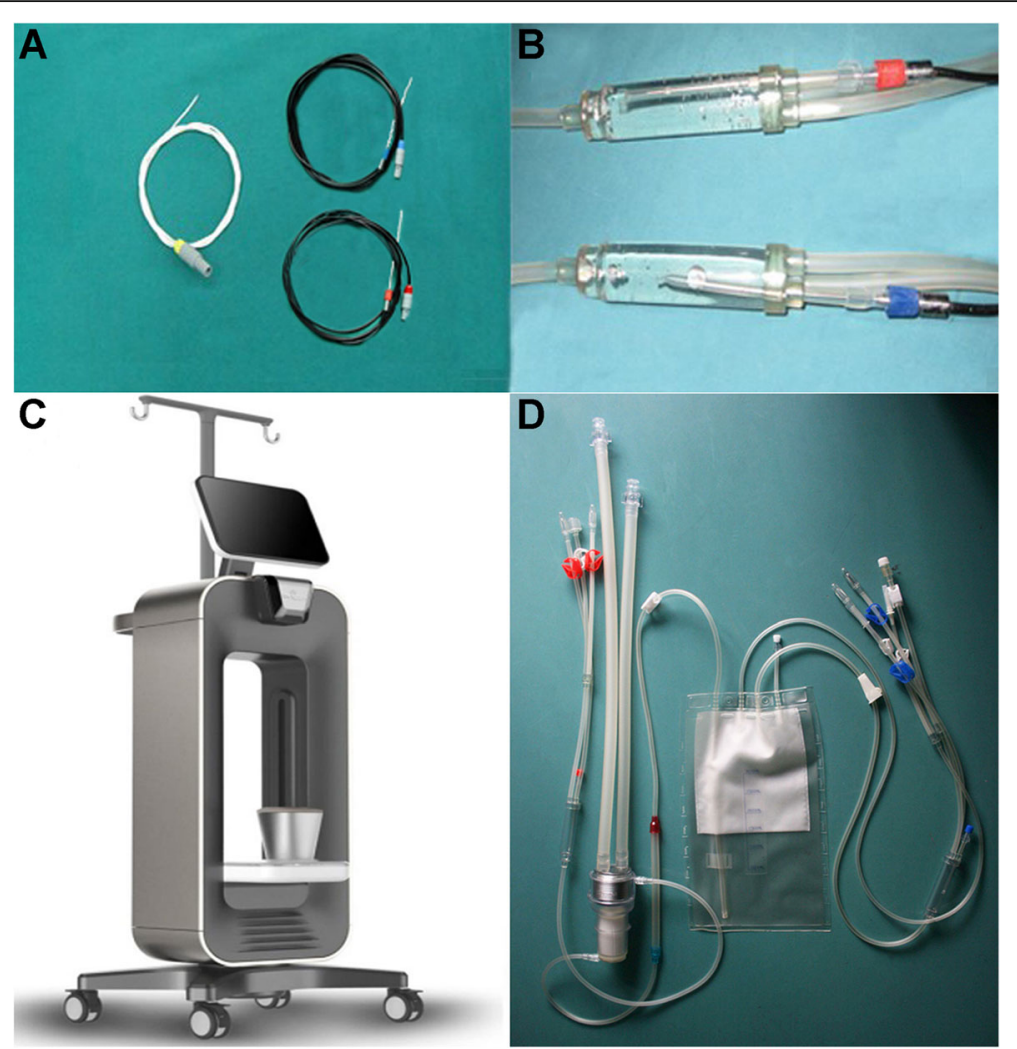

Fig. 2 Illustration of the BR-TRG-II-type HIVEC system for HIVEC. (a) Temperature-monitoring probes. One tip is placed into a fixed water sac linked to an infusion tube near an inlet (red cap) or outflow catheters (blue cap) at the top of a $24 \mathrm{~F}$ 3-way Foley catheter (yellow cap). (b) Temperature-monitoring probes location; red cap locates near the infusion catheters, and blue cap locates near the outflow catheters. (c) The device. $\mathbf{d})$ The tubes

$600 \mathrm{ml}$ ) of sterile saline, as previously reported $[6,7]$. The liquid perfusion rate was set as $150-200 \mathrm{ml} / \mathrm{min}$. The treatment temperature and time were set (i.e., $45^{\circ} \mathrm{C}$ for $60 \mathrm{~min}$ ) according to the patient's clinical data.

Before HIVEC, perfusion liquid was adjusted to 350$450 \mathrm{ml}$ (average $400 \mathrm{ml}$ ) at $45^{\circ} \mathrm{C}$ within the bladder according to the perfusion pressure and the patient's subjective experience. The amount of perfusion fluid within the bladder cavity could be increased or decreased according to the patient's subjective experience, and the temperature change was monitored closely by the temperature probe. The patient's vital signs (including blood pressure, heart rate, respiratory rate, and blood oxygen saturation) were monitored using a G3HJ20025 multi-parameter patient monitor (MINDRAY BioMedical Electronics Co. Ltd., Shenzhen, China). HIVEC treatment was terminated if any accidents happened, such as treatment temperature $>45^{\circ} \mathrm{C}$ or bladder lumen pressure over patients' tolerance during HIVEC. HIVEC was performed once a week for 3 weeks. The $24 \mathrm{~F} 3$-way Foley catheters were retained for 3-5 days for urine drainage after the first session for observing for eventual bleeding of the TUR wound.

\section{Pathological examination}

In all patients, the tumor tissues were taken before HIVEC or 4 weeks after HIVEC and were observed for histological changes by hematoxylin-eosin (H\&E) staining, as described previously $[13,19]$. Resected specimens were reviewed by an experienced pathologist blinded to grouping, as described previously $[13,19]$.

\section{Pharmacokinetics of MMC}

Venous blood (from the venous catheters at $0,15,30$, $45,60,75$, and $90 \mathrm{~min}$ ) and perfusion liquid (from the short circuit outflow catheters of the perfusion system at $0,15,30,45,60,75$, and $90 \mathrm{~min}$ ) samples were collected from 12 patients in the two groups. Perfusion liquid, serum, or MMC standard samples (degassed prior to use) $(200 \mu \mathrm{l})$ were vortexed for $1 \mathrm{~min}$ with $200 \mu \mathrm{l}$ of acetonitrile containing diazepam $(20 \mu \mathrm{g}$; internal standard). The samples were separated by centrifugation at $15,000 \mathrm{rpm}$ for $15 \mathrm{~min}$. The supernatants $(10 \mu \mathrm{l})$ were subjected to high-performance liquid chromatography (HPLC, aLC-20AB, Shimazdu, Kyoto, Japan). The stationary phase was Zorbax RP, and $\mathrm{C}_{18}(250 \times 4.6 \mathrm{~mm}$; particle size $5 \mu \mathrm{m}$ ) packed columns. The analysis was 
performed as previously reported [25], but with some modifications. The mobile phase was a 60:20:20 (\%, volume) solution of $50 \mathrm{mM}$ potassium dihydrogen phosphate buffer solution, acetonitrile, and methanol, $\mathrm{pH}$ 3.0, and filtered using a $0.22-\mu \mathrm{m}$ membrane (Millipore, Billerica, MA, USA). Samples were injected at $1.2 \mathrm{ml} / \mathrm{min}$. The absorption wavelength for detection was $210 \mathrm{~nm}$. The column oven temperature was $35^{\circ} \mathrm{C}$. The linear ranges of the standard curves were $0.10-10.0 \mathrm{mg} / \mathrm{ml}$ for $\mathrm{MMC}$ in the perfusion liquid and $0.50-50.0 \mathrm{ng} / \mathrm{ml}$ for MMC in the serum [26, 27].

\section{Follow-up}

Follow-up was performed by urinary cystoscopic observation at 1 month after TUR and then each 3 months for 1 year. These patients underwent abdominal and pelvic CT scans at 3, 6, and 12 months, or when clinically indicated. After 1 year, follow-up was carried out at 6-month intervals or less frequently if the patients remained without evidence of disease.

\section{Endpoints}

The primary endpoints were tumor recurrence (diagnosed by cystoscopic observation, CT, or MRI), DFS, and cumulative incidence rate (CIR) during follow-up. The adverse effects of the anticancer drugs were graded according to the Common Toxicity Criteria of the National Cancer Institute for Adverse Events (CTCAE) [28].

\section{Statistical analysis}

In the animal part, a minimum of six animals was deemed necessary to reach any conclusion. For the human part, the sample size was not calculated because there was no randomization. This is a convenience sampling of all patients who met the criteria during the study period and agreed to participate in the study. All continuous data were tested for normal distribution using the Kolmogorov-Smirnov test, are presented as mean \pm standard deviation, and were analyzed using the Student's t-test (intergroup comparisons) or repeated measure ANOVA with the LSD post hoc test (intragroup comparisons). Categorical data are presented as frequencies and were analyzed using the Fisher's exact test. CIR and DFS were analyzed using the Kaplan-Meier curve method with the log-rank test. Data were analyzed using SPSS 19.0 (IBM, Armonk, NY, USA). Two-sided $P$-values $<0.05$ were considered statistically significant.

\section{Results}

\section{Animal experimental data}

The animal experiment showed that when using the device set at $44{ }^{\circ} \mathrm{C}$ for $1 \mathrm{~h}$, a temperature of about $43^{\circ} \mathrm{C}$ was achieved in the intravesical cavity without affecting the vital signs of the animals. The bladder mucosa showed slight pathological changes and returned to normal by $1 \mathrm{~h}$ after HIVEC. Setting HIVEC at $46^{\circ} \mathrm{C}$ for $1 \mathrm{~h}$ achieved an intravesical temperature of about $45^{\circ} \mathrm{C}$ and caused slightly increased blood pressure and heart rate, along with bladder mucosa hyperemia and edema, which returned to normal by 3 days after the final HIVEC. Setting the HIVEC at $48^{\circ} \mathrm{C}$ for $1 \mathrm{~h}$ achieved an intravesical temperature of about $47^{\circ} \mathrm{C}$ and caused significant increases in blood pressure and heart rate, along with bladder mucosa pathological changes that did not return to normal by 1 week after HIVEC. Therefore, $45^{\circ} \mathrm{C}$ for 1 $\mathrm{h}$ was used in the clinical study.

\section{Characteristics of the patients}

One hundred and sixty-five patients with bladder cancer were eventually enrolled in this study. There were 108 males and 57 females, with a median age of 51 years (ranging from 37 to 76 years). Of these patients, 128 cases underwent HIVEC after TUR (including four patients with recurrent bladder cancers with a disease-free period of 3-6 months post-TUR), while 37 received HIVEC. There were no significant differences in age, gender, disease course, and tumor location, stage, and size between the two groups (all $P>0.05$ ) (Table 1 ).

\section{Gross outcomes of HIVEC}

HIVEC was successful, with the infusion tube temperature stably controlled at about $45^{\circ} \mathrm{C}$, and an outlet tube temperature of about $43^{\circ} \mathrm{C}$ (Fig. 3). All patients tolerated three sessions of HIVEC. For all patients in the HIVEC groups, gross hematuria stopped after 2 days after the first HIVEC, but slight hematuria lasted for up to one week following the first treatment.

\section{Pharmacokinetics of MMC}

The MMC concentration in the bladder perfusion fluid gradually decreased during treatment from $1 \mathrm{mg} / \mathrm{ml}$ to $0.967 \mathrm{mg} / \mathrm{ml}$ in the HIVEC + TUR group and $0.970 \mathrm{mg} / \mathrm{ml}$ in the HIVEC groups $(\mathrm{P}>0.05)$ (Fig. 4a). The MMC concentration in the serum gradually increased during HIVEC treatment in both groups, to $4.32 \pm 0.11,7.86 \pm 0.14$, $10.08 \pm 0.21$, and $7.56 \pm 0.16 \mathrm{ng} / \mathrm{m}$ at, $15,30,45,60$, and 75 min in the HIVEC + TUR group, which were significantly higher than in the HIVEC group $(3.01 \pm 0.09,5.78 \pm 0.11$, $5.98 \pm 0.12$, and $5.66 \pm 0.13 \mathrm{ng} / \mathrm{ml}$, respectively) (Fig. $4 \mathrm{~b}$ ). The MMC concentration in serum decreased after HIVEC, being all below $3.28 \pm 0.08 \mathrm{ng} / \mathrm{ml}$ at $90 \mathrm{~min}$ (Fig. 4b).

\section{Cystoscopic and histological observation}

In the HIVEC + TUR group, cystoscopy showed no viable tumor lesions, except in 12 patients who had T2 diseases; the lesions were showing as grey-white slough on the bladder mucosa around the lesions, accompanied by congestion and edema. In the HIVEC group, all patients showed 
Table 1 Characteristics of the patients with bladder cancer

\begin{tabular}{|c|c|c|c|}
\hline & HIVEC+TUR $(n=128)$ & HIVEC $(n=37)$ & $P$ \\
\hline Age (years) & $50.7 \pm 1.9(37-66)$ & $51.6 \pm 2.3(39-66)$ & 0.07 \\
\hline \multicolumn{4}{|l|}{ Sex, $n(\%)$} \\
\hline Male & $86(67.2)$ & $22(59.5)$ & 0.09 \\
\hline Female & $42(32.8)$ & $15(40.5)$ & 0.07 \\
\hline Disease course (days) & $11.4 \pm 1.3$ & $11.3 \pm 1.6$ & 0.07 \\
\hline \multicolumn{4}{|l|}{ Tumor location, $n$ (\%) } \\
\hline Side wall & $35(27.3)$ & $1(2.7)$ & 0.06 \\
\hline Posterior wall & $27(21.1)$ & $2(5.4)$ & 0.08 \\
\hline Top area & $19(14.8)$ & $1(2.7)$ & 0.08 \\
\hline Triangle area & $10(7.8)$ & $17(45.9)$ & 0.06 \\
\hline$\geq$ two tumors & $37(28.9)$ & $16(43.2)$ & 0.07 \\
\hline \multicolumn{4}{|l|}{ Tumor size, $n$ (\%) } \\
\hline$\geq 0.5 \mathrm{~cm}$ & $66(51.6)$ & $28(75.6)$ & 0.07 \\
\hline$<0.5 \mathrm{~cm}$ & $62(48.4)$ & $9(24.4)$ & 0.09 \\
\hline \multicolumn{4}{|l|}{ Tumor stage, $n(\%)$} \\
\hline Tis & $13(10.2)$ & 0 & 0.06 \\
\hline $\mathrm{T}_{1}$ & $73(57.0)$ & $9(24.3)$ & 0.06 \\
\hline $\mathrm{T}_{2}$ & $42(32.8)$ & $28(75.7)$ & 0.08 \\
\hline \multicolumn{4}{|c|}{ Tumor differentiation, n (\%) } \\
\hline $\mathrm{G}_{1}$ & $41(32.0)$ & $11(29.7)$ & 0.08 \\
\hline$G_{2}$ & $54(42.2)$ & $14(37.8)$ & 0.08 \\
\hline $\mathrm{G}_{3}$ & $33(25.8)$ & $12(32.4)$ & 0.75 \\
\hline
\end{tabular}

HIVEC: bladder intracavitary hyperthermic perfusion chemotherapy cystoscopic findings consistent with the findings observed in those with residual lesions in the HIVEC + TUR group. Pathological examination showed that the lesions presented degenerative necrosis and inflammatory cells such as eosinophils infiltrating the lamina propria (Fig. 5a) Complete necrosis accompanied by local vascular changes (such as necrosis and thrombosis) in the tumor small vessels were also observed, as well as stromal hemorrhage (Fig. 5b).

\section{Follow-up}

All patients were followed for at least 6 months. The median follow-up was 41.9 months (6.5 to 110 months) for the HIVEC + TUR group and 42.3 months (10.5 to 99.7 months) for the HIVEC group $(P>0.05)$. All patients were still alive at the moment of writing this paper. In the HIVEC + TUR group, cystoscopic observation showed tumor recurrence in 14 patients after HIVEC, which included nine patients with remaining tumor after HIVEC + TUR. The CIR was $10.9 \%$ (14 out of 128 patients). The mean DFS was $39 \pm 3.21$ months (ranging from 8 to 78 months), and the DFS rate was $89.1 \%$ during follow-up (Fig. 6a b). In the HIVEC group, bladder tumor numbers were decreased in 78.4\% (29/37) patients or disappeared in $16.2 \%(6 / 37)$ patients; $51.35 \%(19 / 37)$ patients could undergo TUR 1-2 months after HIVEC.

\section{Adverse effect}

No gastrointestinal events or bone marrow suppression occurred. Laboratory tests showed no significant changes in blood, electrolytes, and liver and kidney functions

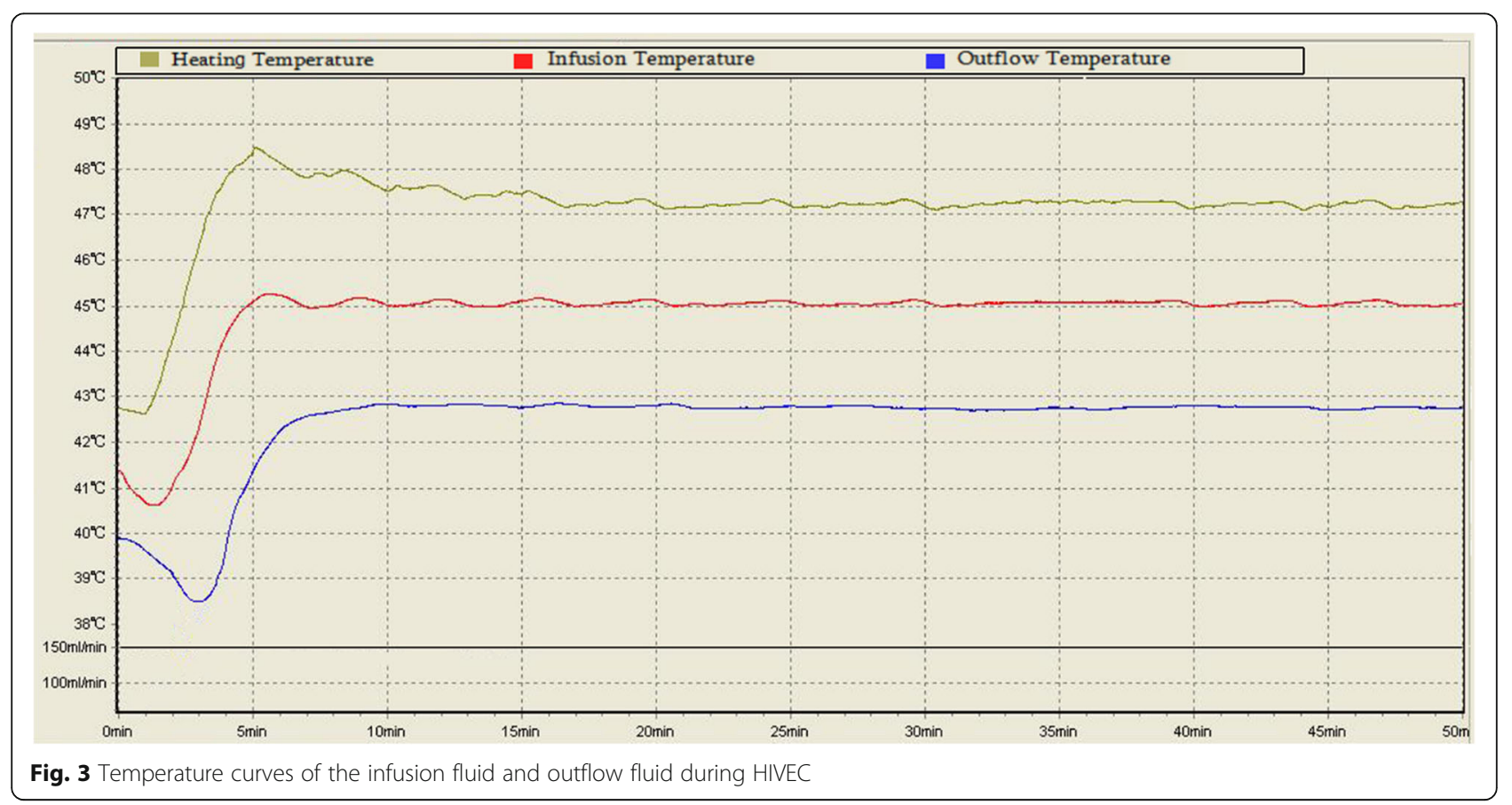




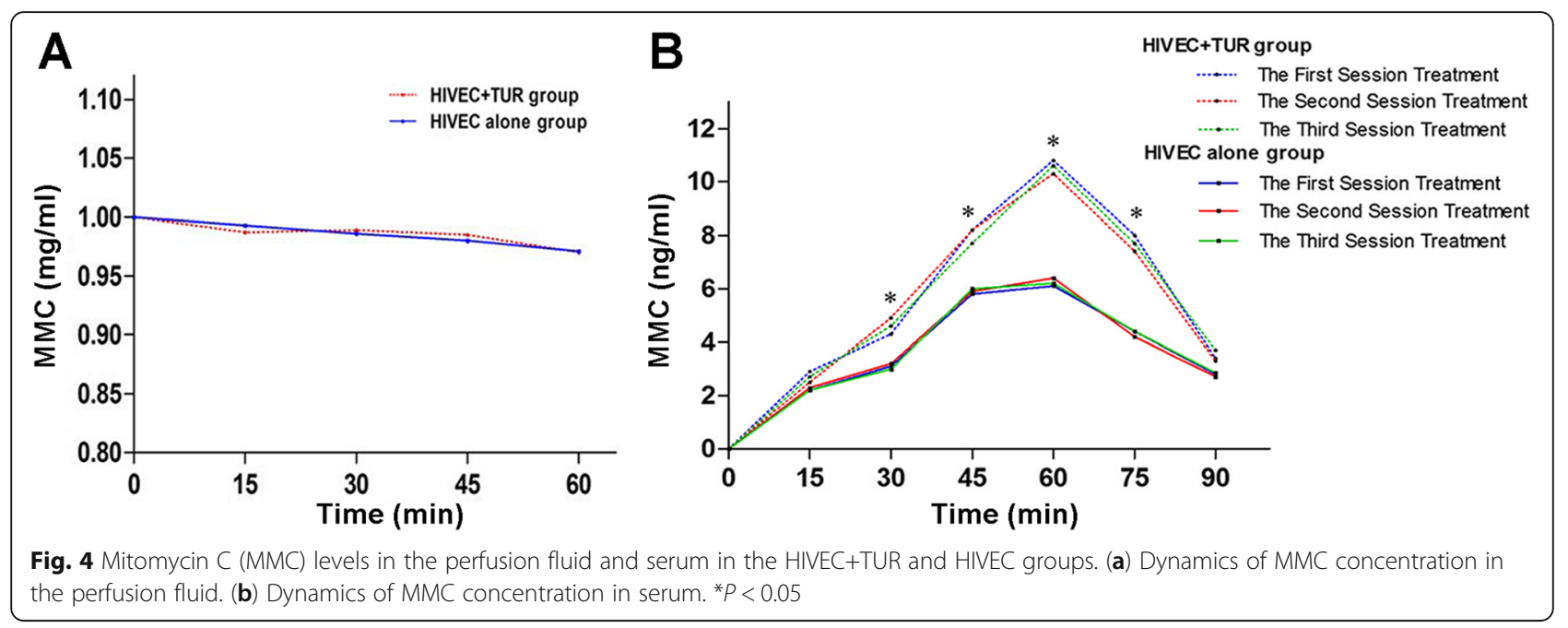

after treatment in all patients. There were no genitourinary or dermatologic adverse reactions such as bladder spasms, chemical cystitis, or chemical irritation of scrotal skin in all patients.

\section{Discussion}

Bladder HIVEC has good effectiveness for bladder cancer [7-13, 19, 29], but the precision and convenient application of conventional HIVEC systems are unsatisfactory. Therefore, this study aimed first to examine the safety of a new HIVEC device (BR-TRG-II-type) in pigs, and then to perform a preliminary clinical trial in patients with bladder cancer. The results showed that the BR-TRG-II-type HIVEC device could be used for the treatment of bladder cancer. Nevertheless, the results need to be confirmed in patients with different cancer stages. Of note, HIVEC is an experimental treatment that is not currently included in any treatment guideline. Nevertheless, a number of studies using different, less accurate HIVEC systems have been performed $[7-13,19,29]$, and this approach could eventually be included in bladder cancer treatment guidelines. Since cystectomy cannot be performed in some patients [30], TUR combined with intravesical HIVEC could be a good option for these cases.

The most important physicians' concern during any treatment involving hyperthermia is setting an adequate temperature. Indeed, too high temperature will cause thermal damage, while too low temperature will not achieve the optimal therapeutic effects. Complicating the issue is the fact that in HIVEC, different body compartments will require different temperatures. In HIPEC, the intra-abdominal temperature generally does not exceed $43{ }^{\circ} \mathrm{C}$ because of the risk of intestinal adhesions and obstruction. On the other hand, for intravesical HIVEC, the temperature is usually set to $45^{\circ} \mathrm{C}$ because bladder mucosa damage recovers fast $[3,9,12,14,26,31]$. In the present paper, the preclinical experiments in pigs showed that the BR-TRG-II-type HIVEC device could meet the requirements for precise temperature control, heating, and cooling, hence ensuring stable, secure,

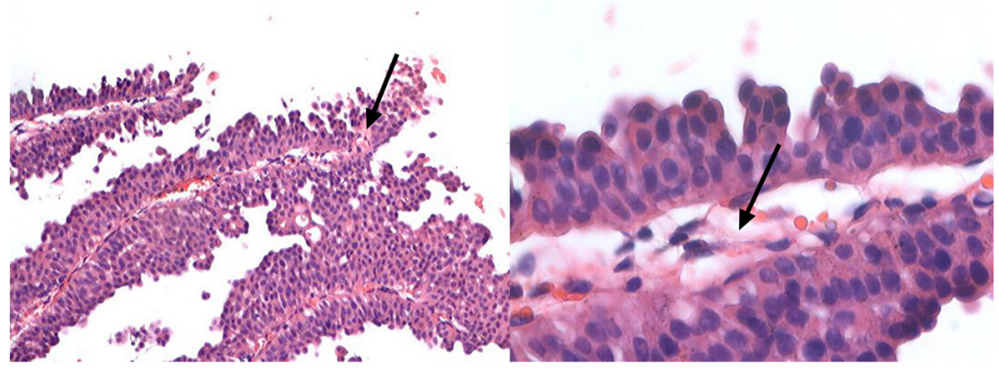

Fig. 5 Histological change after HIVEC in the HIVEC groups. (a) Histological examination showed cancer cell degenerative necrosis, inflammatory cells (sometimes including numerous eosinophils (arrow)) (hematoxylin and eosin, $\times 100$ ). (b) Histological examination showed tumor-infiltrating the lamina propria, but with complete necrosis accompanied by local vascular changes (such as necrosis and thrombosis (arrow) in the small tumor vessels, and hemorrhage into the stroma (hematoxylin and eosin staining, $\times 400$ ) 

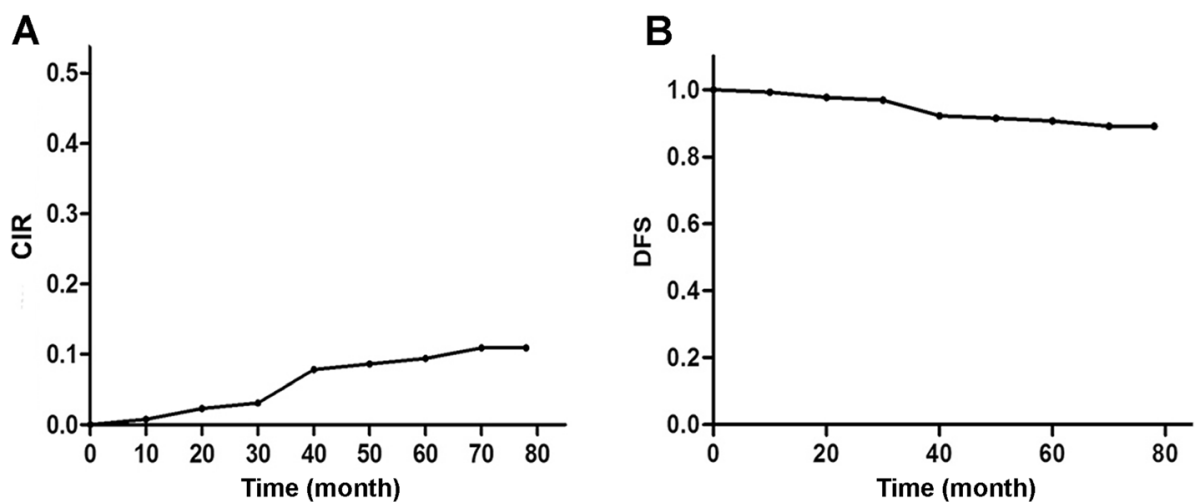

Fig. 6 Kaplan-Meier curves of cumulative incidence rate (CIR) and disease-free survival (DFS) for patients with bladder HIVEC after TUR. a KaplanMeier curves of cumulative incidence rate (CIR), and the CIR was 10.9\% (14 out of 128 patients) for patients with bladder HIVEC after TUR. b Kaplan-Meier curves of disease-free survival (DFS), and the mean DFS was 39.0 1.2 months (ranging from 8 to 78 months), and the DFS rate was 89.1\% during follow-up for patients with bladder HIVEC after TUR

reliable, and convenient application in the clinical setting. Furthermore, the experiments in pigs revealed that intravesical HIVEC at $45^{\circ} \mathrm{C}$ for $1 \mathrm{~h}$ did not affect vital signs; the bladder mucosa showed only slight pathological changes, which returned to normal within $1 \mathrm{~h}$ after HIVEC completion.

Following the animal study, the preliminary clinical study and the results showed that HIVEC using the BRTRG-II-type HIVEC device was feasible in a clinical setting, without any cases of postoperative deaths or serious complications. Gross hematuria disappeared after HIVEC in all patients, bladder lesions were smaller or even disappeared, and $>50 \%$ of the patients who were initially unsuitable for TUR got the chance to receive TUR after HIVEC, as supported by previous reports that revealed the advantages of HIVEC [4-9, 11-19, 32].

The use of intravesical MMC was tried in a number of previous studies $[6-9,11,12]$. Those studies used an MMC dose of at most $60 \mathrm{mg}$ in $60 \mathrm{ml}$ of saline (i.e., MMC at $1 \mathrm{mg} / \mathrm{ml}$ ), which is considered safe and effective in clinical practice $[6-9,11,12]$, but the knowledge of the vesical absorption rate of chemotherapeutic drugs is limited at best. In fact, high MMC concentrations has little relationship with the therapeutic effects $[11,15,16,18,26]$. In addition, the biological effects of cytotoxic drugs under high temperatures are poorly known. In the absence of concrete knowledge, we tested the use of continuous circulation of a fixed dose of chemotherapeutic drugs $(60$ $\mathrm{mg}$ ) in a volume of $500-700 \mathrm{ml}$. In this preliminary trial, this dose was safe and effective. The absorption of MMC is related to damage to the bladder mucosa during intravesical HIVEC, and MMC concentration remains excessively high in the absence of mucosal damage, potentially leading to cystitis [6]. Taking those considerations into account, MMC concentration was $0.1 \mathrm{mg} / \mathrm{ml}$ in the present study, which is much higher than the $0.002 \mathrm{mg} / \mathrm{ml}(10$ $\mathrm{mg} / 5000 \mathrm{ml}$ ) used in HIPEC and systemic chemotherapy. In the preliminary studies, using different concentrations of MMC did not improve the therapeutic effects, but there were no adverse events either. Nevertheless, in the present study, intravesical HIVEC using high MMC concentration ensured a high, constant, and sustained local chemotherapeutic drug concentration thought to achieve the best chemotherapeutic efficacy. In the present study, the MMC concentration in the perfusion fluid was gradually decreased over HIVEC time, probably due to urine dilution or/and systemic absorption. Indeed, serum MMC levels increased during HIVEC and decreased after HIVEC, but previous studies in humans indicated that serum MMC concentrations after HIVEC do not reach a critical toxic threshold $[8,9]$. In the present study, serum MMC concentrations peaked at $60 \mathrm{~min}$, and the serum MMC levels stayed below the toxic value, and the half-life of MMC is $30-50$ min $[7,8]$. Accordingly with the higher absorption in the presence of mucosal damage, serum MMC concentrations in the TUR+ HIVEC group were significantly higher than those in the HIVEC group.

The effects of temperature on mucosal blood vessels could lead to plasma exudation and interstitial hemorrhage. There is also a risk that these vascular changes exacerbated the direct thermal injury to the lamina propria, sometimes resulting in necrosis with exfoliation of the epithelium $[6,7,14,18]$. In the HIVEC group, complete necrosis accompanied by local vascular changes (such as necrosis and thrombosis) in the small tumor vessels and hemorrhage into the stroma was indeed observed. Because tumor vessels are more susceptible to thermal injury than normal tissue vessels, these changes may be responsible, at least in part, for inhibiting bladder cancer growth $[7,8]$.

It is recommended that HIVEC is performed for at least seven sessions, but there is no standard for intravesical HIVEC in China and worldwide. In the present study, only 
three HIVEC sessions were performed, mainly to study process and to prevent delays of further treatments. Additional treatments were performed for non-responsive patients after three sessions, which could include surgical resection, arterial embolization thermotherapy, intravesical chemotherapy plus immunotherapy, or intravesical HIVEC plus immunotherapy. Additional trials are necessary to determine the best treatment strategies for the treatment of bladder cancer and the exact place of intravesical HIVEC in those strategies.

This device is not without limitation. Since it is based on conductive heating, the temperature of the fluid can be accurately maintained, but the exact temperature of the bladder mucosa cannot be guaranteed due to heat loss by diffusion in adjacent tissues and blood circulation. Meanwhile, this study only tested the feasibility and safety of this device, as well as MMC pharmacokinetics. Because the incidence of bladder cancer is relatively low in China, the inclusion criteria of this study were relatively strict, leading to a relatively small sample size spanning over many years. Future studies with more patients will be performed to validate these results. A control group will also be included.

\section{Conclusion}

In conclusion, it is feasible to use the BR-TRG-II-type HIVEC device for patients with bladder cancers. This treatment tool has good prospects for widespread clinical application in patients with bladder cancer.

\section{Abbreviations}

BCG: Bacillus Calmette-Guerin; CIR: Cumulative incidence rate; CT: Computerized tomography; DFS: Disease-free survival; HIVEC: Hyperthermic intracavitary chemotherapy; MMC: Mitomycin C; MRI: Magnetic resonance imaging; TUR: Transurethral resection

\section{Acknowledgments}

None.

\section{Authors' contributions}

MC B and SZ C performed the development of the device, and the original literature search, and participated in drafting the manuscript. MC B and $\mathrm{HL}$ participated in the design of the study and performed the statistical analysis. $M C B, S Z C, H L, Y F G, Y B W, K P L, Y N T, B H Z$, and WB W participated in by animal experiments and hyperthermic intraperitoneal perfusion chemotherapy (HIVEC). All authors read and approved the final manuscript.

\section{Funding}

The Guangzhou Key Medical Discipline Construction Project (No. 2017), the Guangdong Science and Technology Plan Project (No. 20160918), the Scientific Research Project of Guangzhou Municipal University (No. 1201610061), the Guangzhou Science Technology and Innovation Commission (No. 2014Y2-00152), and the Guangzhou Science Technology and Innovation Commission (No. 2014Y2-00548) provided funding for the completion of this project, including the design and production of highprecision bladder hyperthermic intracavitary chemotherapy device and pipeline system, and the purchase of experimental animals and reagents. The funders had no role in study design, study completion, data analysis, and writing of the manuscript.

\section{Availability of data and materials}

The datasets used and/or analyzed during the current study are available from the corresponding author on reasonable request.

\section{Ethics approval and consent to participate}

This study was approved by the Ethics Committee of Animal Experiments of Guangzhou Medical University (No. GZMU ECAE 20060326), Guangzhou, China:

This study was approved by the Medical Ethics Committee of the Cancer Hospital of Guangzhou Medical University (No. GZMUMEC20060825). Written informed consent was obtained from all patients.

\section{Consent for publication}

Not applicable.

\section{Competing interests}

The authors declare that they have no competing interests.

\section{Author details}

${ }^{1}$ Intracelom Hyperthermic Perfusion Therapy Center, Cancer Hospital of Guangzhou Medical University, No. 78 Hengzhigang Road, Guangzhou, Guangdong 510095, People's Republic of China. ${ }^{2}$ Department of Pharmacy, Guangzhou Dermatology Institute, Guangzhou, Guangdong, People's Republic of China.

Received: 20 February 2019 Accepted: 23 October 2019

Published online: 03 December 2019

References

1. Siegel R, Naishadham D, Jemal A. Cancer statistics, 2012. CA Cancer J Clin. 2012;62(1):10-29.

2. Penson DF. Re: effectiveness of adjuvant chemotherapy for locally advanced bladder Cancer. J Urol. 2016;196(2):352-4.

3. Douglass $L$, Schoenberg M. The future of Intravesical drug delivery for nonmuscle invasive bladder Cancer. Bladder Cancer. 2016;2(3):285-92.

4. Veeratterapillay R, Heer R, Johnson Ml, Persad R, Bach C. High-risk nonmuscle-invasive bladder Cancer-therapy options during Intravesical BCG shortage. Curr Urol Rep. 2016;17(9):68

5. Hayne D, Stockler M, McCombie SP, Chalasani V, Long A, Martin A, et al. BCG+MMC trial: adding mitomycin $C$ to $B C G$ as adjuvant intravesical therapy for high-risk, non-muscle-invasive bladder cancer: a randomised phase III trial (ANZUP 1301). BMC Cancer. 2015;15:432.

6. Inman BA, Stauffer PR, Craciunescu OA, Maccarini PF, Dewhirst MW, Vujaskovic Z. A pilot clinical trial of intravesical mitomycin-C and external deep pelvic hyperthermia for non-muscle-invasive bladder cancer. Int J Hyperth. 2014;30(3):171-5.

7. Colombo R, Salonia A, Leib Z, Pavone-Macaluso M, Engelstein D. Long-term outcomes of a randomized controlled trial comparing thermochemotherapy with mitomycin- $C$ alone as adjuvant treatment for non-muscle-invasive bladder cancer (NMIBC). BJU Int. 2011;107(6):912-8.

8. Paroni R, Salonia A, Lev A, Da Pozzo LF, Cighetti G, Montorsi F, et al. Effect of local hyperthermia of the bladder on mitomycin $C$ pharmacokinetics during intravesical chemotherapy for the treatment of superficial transitional cell carcinoma. Br J Clin Pharmacol. 2001;52(3):273-8.

9. Colombo R, Salonia A, Da Pozzo LF, Naspro R, Freschi M, Paroni R, et al. Combination of intravesical chemotherapy and hyperthermia for the treatment of superficial bladder cancer: preliminary clinical experience. Crit Rev Oncol Hematol. 2003;47(2):127-39.

10. Crezee $\mathrm{H}$, Inman BA. The use of hyperthermia in the treatment of bladder cancer. Int J Hyperth. 2016;32(4):349-50.

11. Geijsen ED, de Reijke TM, Koning CC. Zum Vorde Sive Vording PJ, de la rosette JJ, Rasch CR, et al. combining Mitomycin C and regional $70 \mathrm{MHz}$ hyperthermia in patients with nonmuscle invasive bladder Cancer: a pilot study. J Urol. 2015;194(5):1202-8.

12. Ba M, Cui S, Wang B, Long $H$, Yan Z, Wang $S$, et al. Bladder intracavitary hyperthermic perfusion chemotherapy for the prevention of recurrence of non-muscle invasive bladder cancer after transurethral resection. Oncol Rep. 2017:37(5):2761-70.

13. Soria F, Milla P, Fiorito C, Pisano F, Sogni F, Di Marco M, et al. Efficacy and safety of a new device for intravesical thermochemotherapy in non-grade 3 BCG recurrent NMIBC: a phase I-II study. World J Urol. 2016;34(2):189-95. 
14. Owusu RA, Abern MR, Inman BA. Hyperthermia as adjunct to intravesical chemotherapy for bladder cancer. Biomed Res Int. 2013;2013:262313.

15. Ekin RG, Akarken I, Cakmak O, Tarhan H, Celik O, Ilbey YO, et al. Results of Intravesical chemo-hyperthermia in high-risk non-muscle invasive bladder Cancer. Asian Pac J Cancer Prev. 2015;16(8):3241-5.

16. Sousa A, Pineiro I, Rodriguez S, Aparici V, Monserrat V, Neira P, et al. Recirculant hyperthermic IntraVEsical chemotherapy (HIVEC) in intermediate-high-risk nonmuscle-invasive bladder cancer. Int J Hyperth. 2016;32(4):374-80.

17. Rolevich Al, Zhegalik AG, Mokhort AA, Minich AA, Vasilevich VY, Polyakov SL, et al. Results of a prospective randomized study assessing the efficacy of fluorescent cystoscopy-assisted transurethral resection and single instillation of doxorubicin in patients with non-muscle-invasive bladder cancer. World J Urol. 2017;35(5):745-52.

18. Gofrit ON, Shapiro A, Pode D, Sidi A, Nativ O, Leib Z, et al. Combined local bladder hyperthermia and intravesical chemotherapy for the treatment of high-grade superficial bladder cancer. Urology. 2004;63(3):466-71.

19. Colombo R, Da Pozzo LF, Lev A, Freschi M, Gallus G, Rigatti P. Neoadjuvant combined microwave induced local hyperthermia and topical chemotherapy versus chemotherapy alone for superficial bladder cancer. J Urol. 1996;155(4):1227-32.

20. Ba MC, Cui SZ, Lin SQ, Tang YQ, Wu YB, Wang B, et al. Chemotherapy with laparoscope-assisted continuous circulatory hyperthermic intraperitoneal perfusion for malignant ascites. World J Gastroenterol. 2010;16(15):1901-7.

21. Cui S, Ba M, Tang Y, Liu J, Wu Y, Wang B, et al. B ultrasound-guided hyperthermic intraperitoneal perfusion chemotherapy for the treatment of malignant ascites. Oncol Rep. 2012;28(4):1325-31.

22. Charan J, Kantharia ND. How to calculate sample size in animal studies? J Pharmacol Pharmacother. 2013;4(4):303-6.

23. Festing MF, Altman DG. Guidelines for the design and statistical analysis of experiments using laboratory animals. ILAR J. 2002;43(4):244-58.

24. Festing MF. Design and statistical methods in studies using animal models of development. ILAR J. 2006;47(1):5-14

25. Chen AP, Setser A, Anadkat MJ, Cotliar J, Olsen EA, Garden BC, et al. Grading dermatologic adverse events of cancer treatments: the common terminology criteria for adverse events version 4.0. J Am Acad Dermatol. 2012;67(5):1025-39.

26. Milla P, Fiorito C, Soria F, Arpicco S, Cattel L, Gontero P. Intravesical thermochemotherapy based on conductive heat: a first pharmacokinetic study with mitomycin C in superficial transitional cell carcinoma patients. Cancer Chemother Pharmacol. 2014;73(3):503-9.

27. Abdelaleem EA, Naguib IA, Zaazaa HE, Hussein EA. Development and validation of HPLC and HPTLC methods for determination of Cefoperazone and its related impurities. J Chromatogr Sci. 2016;54(2):179-86.

28. Dwivedi R, Singh M, Kaleekal T, Gupta YK, Tripathi M. Concentration of antiepileptic drugs in persons with epilepsy: a comparative study in serum and saliva. Int J Neurosci. 2016;126(11):972-8.

29. Onishi T, Sugino Y, Shibahara T, Masui S, Yabana T, Sasaki T. Randomized controlled study of the efficacy and safety of continuous saline bladder irrigation after transurethral resection for the treatment of non-muscleinvasive bladder cancer. BJU Int. 2017:119(2):276-82.

30. NCCN. Clinical practice guidelines in oncology (NCCN guidelines). Bladder Cancer. Version 4.2019. National Comprehensive Cancer Network: Fort Washington; 2019

31. van Valenberg $H$, Colombo R, Witjes F. Intravesical radiofrequency-induced hyperthermia combined with chemotherapy for non-muscle-invasive bladder cancer. Int J Hyperth. 2016;32(4):351-62

32. Takai $T$, Inamoto $T$, Komura $K$, Yoshikawa $Y$, Uchimoto $T$, Saito $K$, et al. Feasibility of photodynamic diagnosis for challenging TUR- Bt cases including muscle invasive bladder cancer, BCG failure or 2nd-TUR. Asian Pac J Cancer Prev. 2015;16(6):2297-301.

\section{Publisher's Note}

Springer Nature remains neutral with regard to jurisdictional claims in published maps and institutional affiliations.

Ready to submit your research? Choose BMC and benefit from:

- fast, convenient online submission

- thorough peer review by experienced researchers in your field

- rapid publication on acceptance

- support for research data, including large and complex data types

- gold Open Access which fosters wider collaboration and increased citations

- maximum visibility for your research: over $100 \mathrm{M}$ website views per year

At BMC, research is always in progress.

Learn more biomedcentral.com/submissions 